Hydro-Balanced Stuffing Box Field Test

\author{
Field Test Project Report
}

Date Published: May 28, 1999

Leo A. Giangiacomo, P.E.

Rocky Mountain Oilfield Testing Center

907 N. Poplar, Suite 150

Casper, WY 82601

Distribution A. Approved for public release; Further dissemination unlimited. (Unclassified Unlimited) 


\title{
Hydro-Balanced Stuffing Box Field Test
}

\author{
Test Project Report
}

Date Published: May 28, 1999

Leo A. Giangiacomo, P.E.

PREPARED FOR THE U.S. DEPARTMENT OF ENERGY

ROCKY MOUNTAIN OILFIELD TESTING CENTER

907 N. Poplar, Suite 150

Casper, WY 82601

Work Performed Under RMOTC ERIP Funding 


\section{Disclaimer}

This report was prepared as an account of work sponsored by an agency of the United States Government. Neither the United States Government nor any agency thereof, nor any of their employees, nor any of their contractors, subcontractors, or their employees makes any warranty, express or implied, or assumes any legal liability or responsibility for the accuracy, completeness, or any third party's use or the results of such use of any information, apparatus, product, or process disclosed, or represents that its use would not infringe privately owned rights. Reference herein to any specific commercial product, process, or service by trade name, trademark, manufacturer, or otherwise does not necessarily constitute or imply its endorsement, recommendation, or favoring by the United States Government or any agency thereof, or its contractors or subcontractors. The views and opinions of authors expressed herein do not necessarily state or reflect those of the United States Government or any agency thereof. 
Rocky Mountain Oilfield Testing Center Project Report

HYDROBALANCED STUFFING BOX FIELD TEST

DOE CRADA No. ERIP Funding

Rocky Mountain Oilfield Testing Center

907 N. Poplar, Suite 150

Casper, WY 82601

(307) 261-5000

Report Date:

May 28, 1999

Contract Date:

N/A

Completion Date:

DOE Funding:

March 6, 1999

$\$ 19,600$

Project Manager:

Mark Querin, DOE

Project Engineer:

Leo A. Giangiacomo, P.E., Critique

Other Major Contributors:

Harold Palmour, The Palmour Group

Rob Puckett, P.E., Weatherford

Mike Poythress, Weatherford

Contracting Officer's Representative: Barbara Tucker

RMOTC Report Number

DOE/RMOTC/05.980001 


\begin{abstract}
The Hydro-Balanced Stuffing Box is a seal assembly for polished rod pumping installations commonly used in oil and gas pumping well installations to contain produced well fluids. The improved stuffing box was developed and patented by Harold $\mathrm{H}$. Palmour of The Palmour Group of Livingston, TX. The stuffing box is designed to reduce the incidence of seal leakage and to utilize an environmentally safe fluid, so that if there is any leakage, environmental damage is reduced or eliminated. The unit was tested on two wells at the Rocky Mountain Oilfield Testing Center. During the test period, the performance of the stuffing box was measured by monitoring the pressure on the tubing and the inner chamber with a Barton Two-pen recorder. The amount of safe fluid consumed, fluid leakage at the top of the stuffing box, pressure supplied from the nitrogen bottle, ambient temperature, and polish rod temperature was recorded.

The stuffing box is capable of providing a better seal between well fluids and the environment than conventional stuffing boxes. It allows the polished rod to operate cooler and with lubrication, extending the life of the packing elements, and reducing the amount of attention required to prevent leakage.
\end{abstract}




\section{Executive Summary}

The Hydro-Balanced Stuffing Box is a seal assembly for polished rod pumping installations commonly used in oil and gas pumping well installations to contain produced well fluids. The improved stuffing box was developed and patented by Harold H. Palmour of The Palmour Group of Livingston, TX. The technology is protected by US Patent Number $5,209,405$. The stuffing box is designed to reduce the incidence of seal leakage and to utilize an environmentally safe fluid, so that if there is any leakage, environmental damage is reduced or eliminated. Since the stuffing box is always lubricated, it will increase the life of the packing and polished rod over conventional designs. The technology may be adapted to any make, model, or design of a stuffing box already on the pumping well by using a field retro-fit assembly, thus relieving the operator of having to buy a complete new stuffing box.

The stuffing box seal assembly consists of a primary seal and a secondary seal separated by an environmentally safe fluid-filled inner chamber. The primary seal separates the inner chamber from the atmosphere while the secondary seal separates the inner chamber from the well fluids being pumped to surface in the tubing. The sacrificial fluid is stored in a reservoir and transmitted to the inner chamber through a pressure transmitter and a check valve assembly.

Two models were submitted by the manufacturer, Trico Industries. Both models use flow line or production pressure to hydraulically balance the internal stuffing box pressure with an environmentally safe fluid against the pump pressure in the tubing below. One version uses food grade grease in the internal chamber and the other uses oil.

Two prototype units were installed on rod-pumped stripper wells. These wells produce with a time clock and have a history of packing element wear and stuffing box leaks.

During the test period, the performance of the stuffing box was measured by monitoring the pressure on the tubing and the inner chamber with a Barton Two-pen recorder. The amount of safe fluid consumed was also recorded. Any fluid leakage at the top of the stuffing box was noted. The pressure supplied from the nitrogen bottle was recorded. Ambient temperature was recorded. Polish rod temperature was recorded.

The stuffing box is capable of providing a better seal between well fluids and the environment than conventional stuffing boxes. It allows the polished rod to operate cooler and with lubrication, extending the life of the packing elements, and reducing the amount of attention required to prevent leakage.

It is important to tighten the packing elements correctly. This prevents loss of safe fluid from the inner chamber to either the environment or to the well fluids below. Tightening the primary packing correctly also helps to maintain the inner chamber pressure above the tubing pressure for proper stuffing box operation. When the packing bolts were tightened the exact same distance using a ruler, better performance was obtained.

When the Hydro-Balanced Stuffing Box is installed and adjusted properly, it is capable of significantly reduce the spillage of well fluids from the stuffing box for rod pumped wells, compared to the conventional stuffing box design. The lubrication system should also result in energy savings for the pump motor. 


\section{General Description}

The Hydro-Balanced Stuffing Box is a seal assembly for polished rod pumping installations commonly used in oil and gas pumping well installations to contain produced well fluids. The improved stuffing box was developed and patented by Harold H. Palmour of The Palmour Group of Livingston, TX. The technology is protected by US Patent Number 5,209,405. The equipment to be tested was manufactured by Trico Industries, Inc., now part of Weatherford Artificial Lift Systems of Houston, TX.

The invention was originally submitted by Mr. Palmour to the Office of Technology Innovation of the National Institute of Standards and Technology (NIST), a component of the joint NIST - Department of Energy (DOE) Energy Related Inventions Program (ERIP). The submission was assigned NIST Control Number 015460 . OTI evaluated the invention for its technical validity, energy impact, and commercial feasibility. The invention was recommended to ERIP as worthy of appropriate government support. ERIP then funded the RMOTC field test.

Two models were submitted for testing by Trico Industries. Both rely on flow line or production pressure to hydraulically balance the internal stuffing box pressure with an environmentally safe fluid against the pump pressure in the tubing below. One version uses food grade grease in the internal chamber. The other version uses oil. Both of the fluids are environmentally friendly.

The stuffing box is designed to reduce the incidence of seal leakage and to utilize an environmentally safe fluid, so that if there is any leakage, environmental damage is reduced or eliminated. Since the stuffing box is always lubricated, it will increase the life of the packing and polished rod over conventional designs.

\section{Design}

The stuffing box seal assembly consists of a primary seal and a secondary seal separated by an environmentally safe fluid-filled inner chamber. The primary seal separates the inner chamber from the atmosphere while the secondary seal separates the inner chamber from the well fluids being pumped to surface in the tubing. The sacrificial fluid is stored in a reservoir and transmitted to the inner chamber through a pressure transmitter and a check valve assembly. The pressure transmitter consists of spring-loaded piston and connecting ports. The ports communicate well fluids to the spring side and safe fluid to the piston side of the pressure transmitter. Thus, the transmitter assembly maintains at all times a slightly higher pressure in the inner chamber containing the safe fluids than in the well fluids being pumped. The secondary seal thus remains balanced so that no leakage should occur across this seal. If the secondary seal fails, the safe fluid would be lost to the producing well stream. Eventually the primary seal will wear and can leak, since it is not pressure balanced. In this event, only safe fluid would be lost to the environment. 
There are two versions of the stuffing box; a grease version and an oil version. The function of each stuffing box is essentially the same, however the two versions utilize a different safe fluid.

\section{Grease Version}

A drawing of the grease version is shown in Figure 1. The grease version can be pressured with a grease gun to maintain the positive pressure in the inner

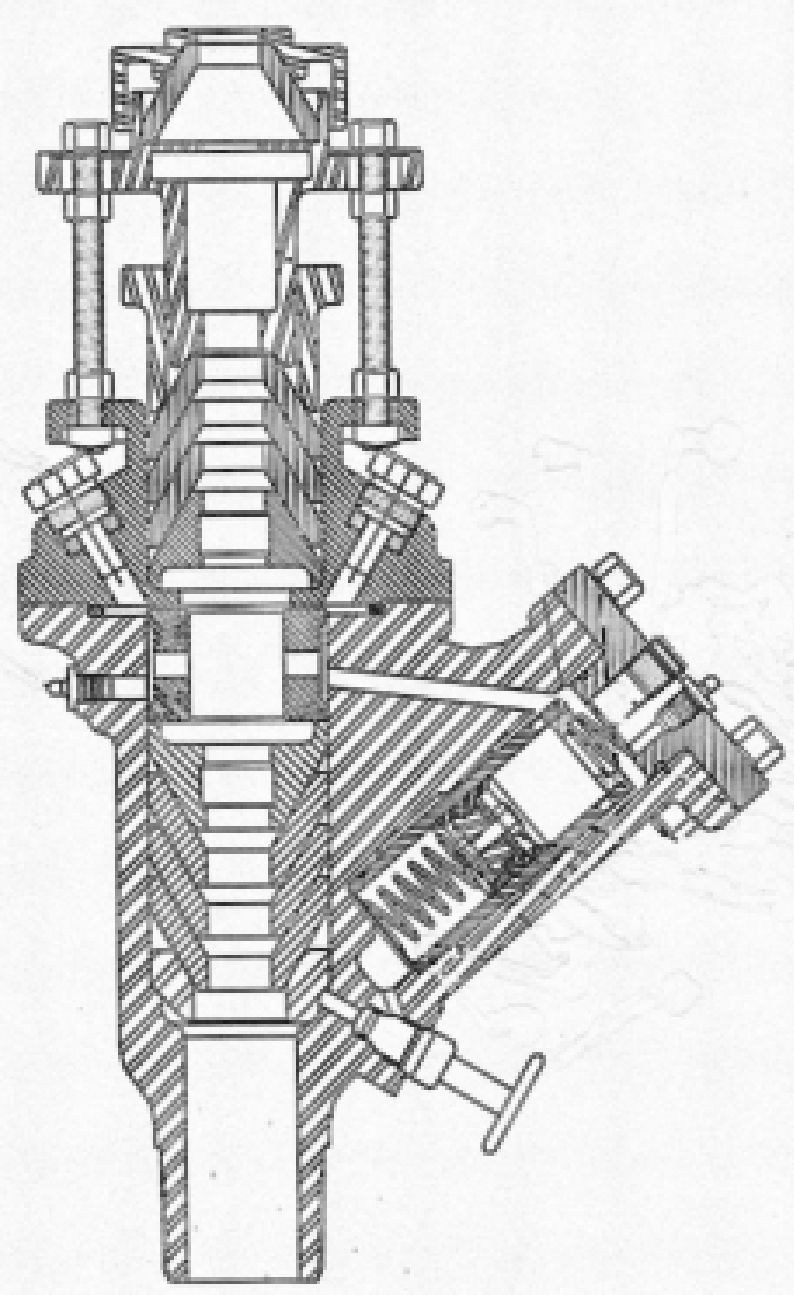

Figure 1 Hydro-Balanced Stuffing Box, Grease Version chamber. It does not require pressure support from the casing to energize the grease reservoir. As long as the primary seal is not leaking, the grease version functions the same as the oil version. However, after an extended period, the packing seals will begin to leak, and the grease will begin to leak out. As it does, the piston assembly will move up and eventually reach the end of its travel and stop. If the leak is not noticed, and the grease supply replenished, well fluids will eventually begin to leak past the secondary and primary seals. The grease version will require more frequent charging with a grease gun, while the fluid version would refill automatically from the fluid reservoir. In either case, if there were a leakage to the atmosphere, the cleanup costs would be greatly reduced if not eliminated.

The design for the level indicator is a thin solid bar approximately $1 / 8$ " in diameter and 8 " long. It should be threaded at one end and fitted with a nut. It can be placed inside a standard 1/4" NPT tubing fitting less the ferrule. Small o-rings can be placed around the bar inside the fitting and screwed down to create the seal. The nut will prevent the bar from exiting the tubing. The male end of the fitting can be screwed into the grease cap where the pressure gauge is located. The bar can be inserted until it touches the piston prior to operation. Some adjustment is needed to keep the bleeder valve, gauge, and 
piston indicator all attached to the grease cap. It is important to choose the correct size o-rings to make this assembly work correctly.

\section{Oil Version}

The oil version is an automatic feed system. A drawing of the stuffing box is presented in Figure 2. The design of the oil version is such that the casing

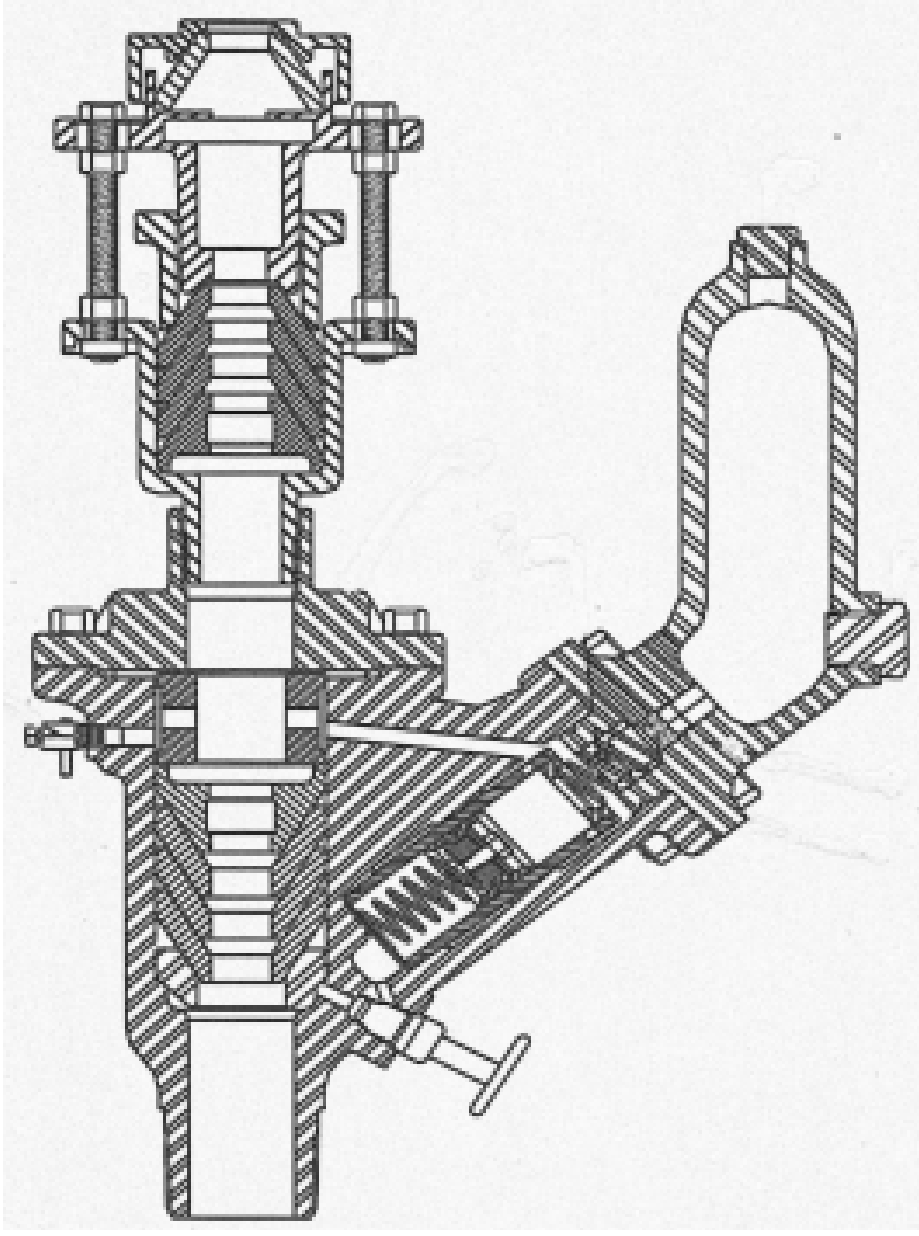
pressure is used to maintain a constant positive pressure on fluid reservoir, and ensure that the inner chamber is constantly replenished with fluid from the reservoir. If this is not possible, an artificial pressure source must be used to pressure the fluid reservoir. Due to its automatic feed system, it can be left unattended for a longer period of time than the grease version. An automatic low-level shut off switch can be used to automatically shut down the pumping unit if the reservoir containing the safe fluid runs dry.

The oil level in the reservoir can be monitored with a sight glass. Figure 3 shows the sight glass installation.

Figure 2 Hydro-Balanced Stuffing Box, Oil Version

\section{Operation}

Under normal operating conditions, the pressure from the produced well fluid is transmitted from under the seal to the inner chamber through the pressure transmitter. It then balances the pressure across the secondary packing, so that leak potential is minimized. The pressure differential is shifted to the primary packing where the environmentally safe fluid is the only fluid that can leak from the stuffing box.

\section{Benefits}

Oil that leaks from a stuffing box is considered lost production. If one barrel of oil is leaked from a stuffing box each year, and if 100,000 wells develop leaks in the 
stuffing box per year in the United States, the overall impact of lost production would be 100,000 barrels. If the well could produce one barrel of oil while the leaking stuffing box seals are being changed out, an additional 100,000 barrels of production would be lost. At $\$ 15$ per barrel, the value of the lost production would be $\$ 3$ million. The contaminated soil must also be cleaned up, although the exact cost to do this would be difficult to quantify.

If any fluid is leaked to the environment, it will be environmentally safe fluid. This will significantly reduce the environmental damage caused by leaking stuffing boxes and lower, if not eliminate, the cost of cleanup.

Since the lubricated seals will operate at lower temperature and cause less wear, the life of the polished rod and packing will be significantly increased over a conventional stuffing box design. Input horsepower will be also be lower due to lowered friction between the rod and packing.

\section{Test Design}

The two prototype units were installed on rod-pumped stripper wells. These wells produce with a time clock and have a history of packing element wear and stuffing box leaks. A Barton two-pen recorder with two static pressure transducers was used to monitor the pressure on either side of the secondary seal. Safe fluid levels and fluid usage was monitored. The stuffing boxes were to be used for a two-month period with daily readings for the first week, and twice-aweek readings for the remainder of the test period.

\section{Equipment Installation}

The grease version of the stuffing box was installed on Well 62AX3 on August 26 and 27, 1998 by a Trico Weatherford representative according to the following recommended procedure:

1. Turn off the pumping unit and apply the brake.

2. Set polish rod clamp as is normally done when changing a regular stuffing box.

3. Make sure proper safety equipment is in place prior to installing the box.

4. Remove the six bolts holding the top stuffing box components to the base, and set components aside.

5. Slide the base over the polish rod and rotate assembly to tighten tubing threads. Use a proper tubing thread lubricant/sealant. Remove stem assemblies from the shipping box, and install side ports on the base. An o-ring lubricant and thread lubricant should be used. (Vaseline for the o-ring, and a proper thread lubricant is recommended.) Tighten stem assemblies in place. An excessive amount of torque is not required.

6. Remove the top packing retainer from the I.D. of the base and set aside.

7. Remove the cone packing and beveled adjusting ring from the shipping box. Place adjusting ring into base and install packing with smaller I.D. facing down onto the adjusting ring. Stagger the slit in the rings so that they are not all aligned.

8. Replace the top retainer in the base I.D. on top of the packing.

9. Make sure the large o-ring is in place on the base flange. (Apply an o-ring lubricant.)

10. Reinstall top flange with the stuffing box components that were removed earlier. Torque 6 bolts in an alternating pattern to approximately $150 \mathrm{ft} \mathrm{lbs}$.

11. Disassemble top stuffing box components (do not remove flange) and install standard cone packing. 
12. Install the flowline shut-off valve in the port on the bottom side of the base. Tighten valve snugly. Do not excessively torque valve.

13. Remove the nipple, tee, bushing, gauge, and bleeder from the shipping box and install. Use Teflon tape or proper thread sealant when installing components.

14. Open the bleeder valve, and pump the assembly full with the Jet-Lube grease until the grease exists the bleed valve.

15. When full, close the bleed valve. Pump more grease into the base until a pressure rise is noticed on the gauge (around $50 \mathrm{psi}$ ). Do not overly pressurize the system.

16. Open the flowline shut-off valve at the bottom side of the base.

17. Tighten the packing to prevent any grease from escaping from the top of the box.

18. The Hydro-Balanced Stuffing Box is now ready for operation.

19. Start the unit and allow the polish rod to reciprocate through the stuffing box several times. Lightly adjust the bolts on the top of the box to tighten the packing if necessary.

The grease level indicator that was supplied was not installed since there was a danger of the internal pressure ejecting the indicator out of the housing and presenting a safety hazard. The installation of a nut on the bottom of the bar was recommended to prevent the possible problem. The grease was filled to the same pressure each time using the pressure gauge. The completed installation can be seen in Figure 4.

The oil version of the stuffing box was installed on well 12AX11 on August 26 and 27, 1998 by a Trico Weatherford representative according to the following recommended procedure:

1. Turn off the pumping unit and apply the brake.

2. Set polish rod clamp as is normally done when changing a regular stuffing box.

3. Make sure proper safety equipment is in place prior to installing the box.

4. Remove the six bolts holding the top stuffing box components to the base.

5. Slide the base over the polish rod and rotate assembly to tighten tubing threads. Use a proper tubing thread lubricant/sealant. Remove stem assemblies from the shipping box, and install side ports on the base. An o-ring lubricant and thread lubricant should be used. (Vaseline for the o-ring, and a proper thread lubricant is recommended.) Tighten stem assemblies in place. An excessive amount of torque is not required.

6. Remove the top packing retainer from the I.D. of the base and set aside.

7. Remove the cone packing and beveled adjusting ring from the shipping box. Place adjusting ring into base and install packing with smaller I.D. facing down onto the adjusting ring. Stagger the slit in the rings so that they are not all aligned.

8. Pour Hydra-Blu hydraulic fluid into the base until the assembly is full.

9. Replace the top retainer in the base I.D.

10. Make sure the large $o$-ring is in place on the base flange.

11. Reinstall top flange with the stuffing box components that were removed earlier. Torque 6 bolts in an alternating pattern to approximately $150 \mathrm{ft}$ lbs.

12. Disassemble top stuffing box components (do not remove flange) and install standard cone packing.

13. Install the flowline shut-off valve in the port on the bottom side of the base. Tighten valve snugly. Do not excessively torque valve.

14. Attach required equipment to the reservoir.

15. Remove the fill cap and fill reservoir to approximately the top port where the accessory equipment is installed (or pipe plug if no accessory equipment is used).

16. Replace the top fill cap.

17. Open the flowline shut-off valve at the bottom side of the base.

18. The Hydro-Balanced Stuffing Box is now ready for operation.

19. Start the unit and allow the polish rod to reciprocate through the stuffing box several times. Lightly adjust the bolts on the top of the box to tighten the packing if necessary. 
The preferred method is to allow some of the fluid to actually flow out when the well pressure reaches its operating pressure, and then to tighten the bolts just enough to stop the leakage. This will minimize friction on the polish rod and reduce excessive wear.

The completed installation of the oil version can be seen in Figure 3.

The stuffing boxes were operated from late August until mid November while the technicians familiarized themselves with their use and assembled the test apparatus. On October 1, 1998, the fluid level monitoring equipment was delivered and installed shortly thereafter. Only minor wear was observed on the secondary packing at this time.

A Barton two-pen pressure recorder was installed on 12AX11. The pressure recorder showed the same pressure on the inner chamber as on the tubing. When nitrogen pressure was applied to the safe fluid reservoir, the fluid in the reservoir was quickly depleted. This took only 4 or 5 pump strokes. The nitrogen pressure was removed, and the situation analyzed and discussed with the manufacturer. Weather conditions limited well access for several weeks.

It was decided that the secondary packing needed to be tightened to prevent the loss of safe fluid from the middle chamber into the well fluids. They were tightened to within three turns of being fully tightened. Nitrogen pressure was set slightly above the minimum pressure during the pump stroke.

Meanwhile refinements to the Barton pressure gauge setup were completed and a satisfactory monitoring system completed for the oil version on Well 12AX11. A similar unit was then constructed and installed on Well 62AX3. Light oil was used to fill the lines and prevent grease from setting up in the lines during cold weather. By mid November, the test setup appeared to be working well enough to start the test. New packing was installed, although only minor wear was observed as a result of lubricated operation for almost 3 months. Monitoring began on November 13, 1998. 


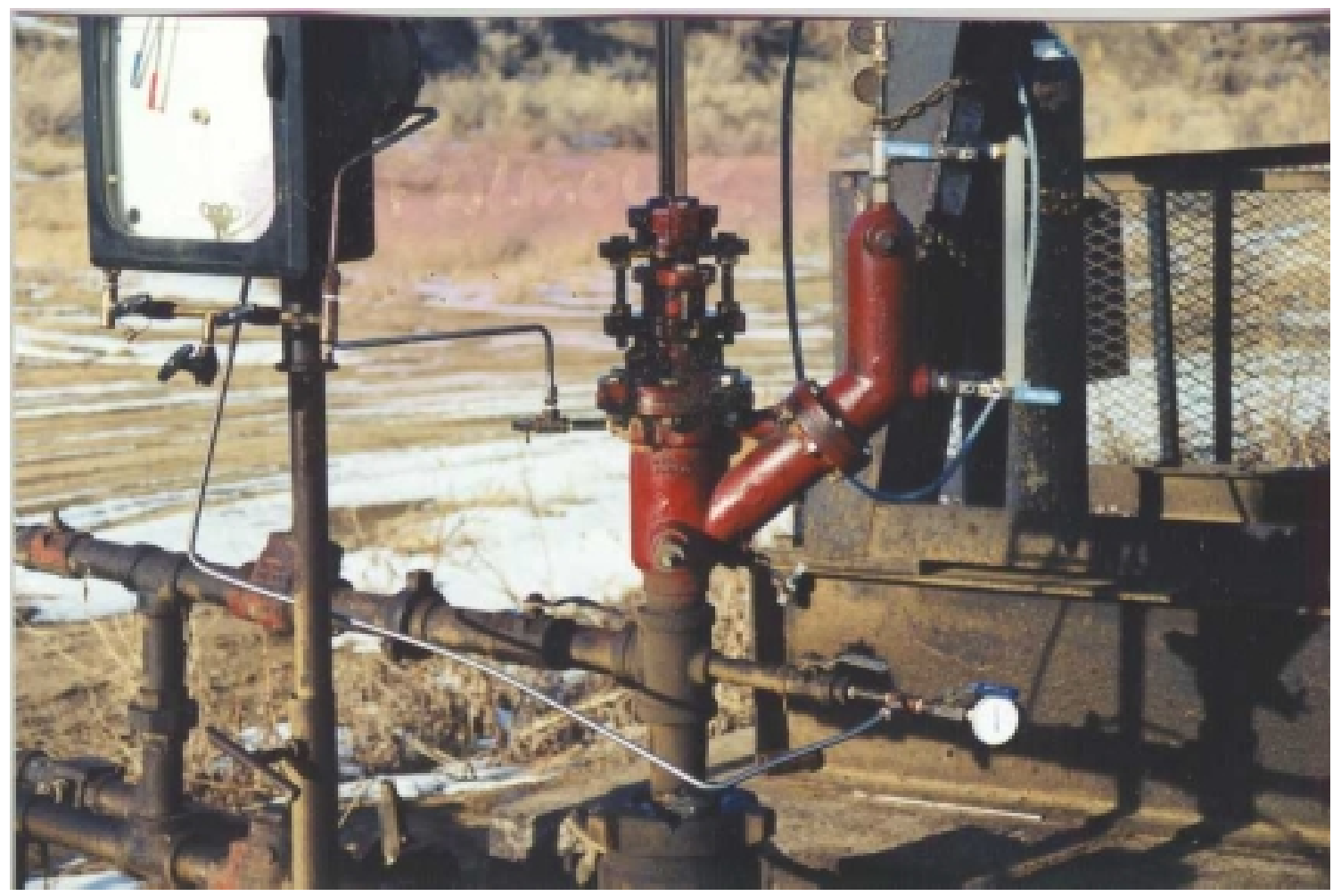

Figure 3 12AX11 Fluid Version Installation

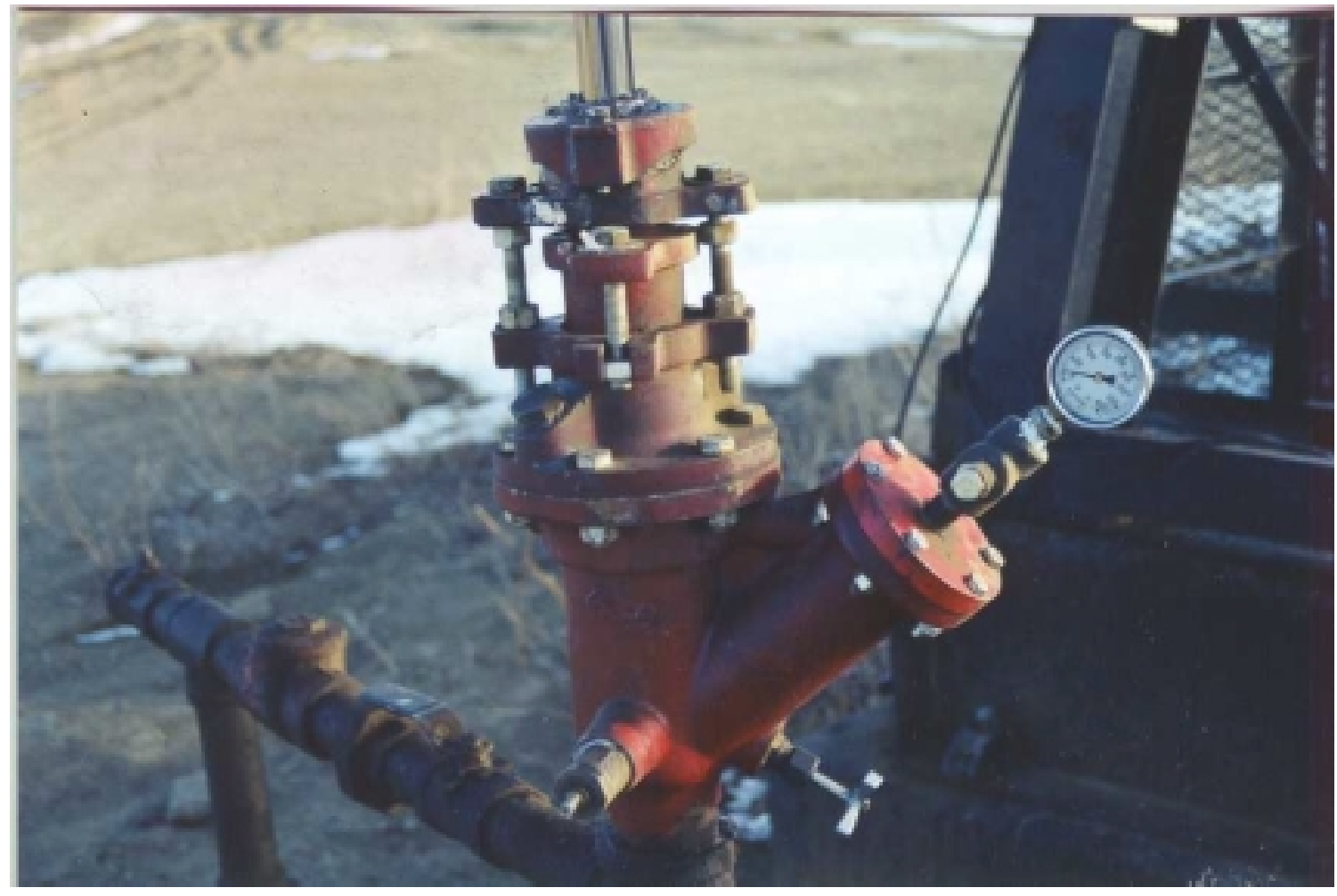

Figure 4 62A3 Grease Version Installation 


\section{Test Results}

During the test period, the performance of the stuffing box was measured by monitoring the pressure on the tubing and the inner chamber with a Barton Twopen recorder. The amount of safe fluid that needed to be added was also recorded. Any fluid leakage at the top of the stuffing box was noted. The pressure supplied from the nitrogen bottle was recorded. Ambient temperature was recorded. Polish rod temperature was recorded. These data were plotted for each well.

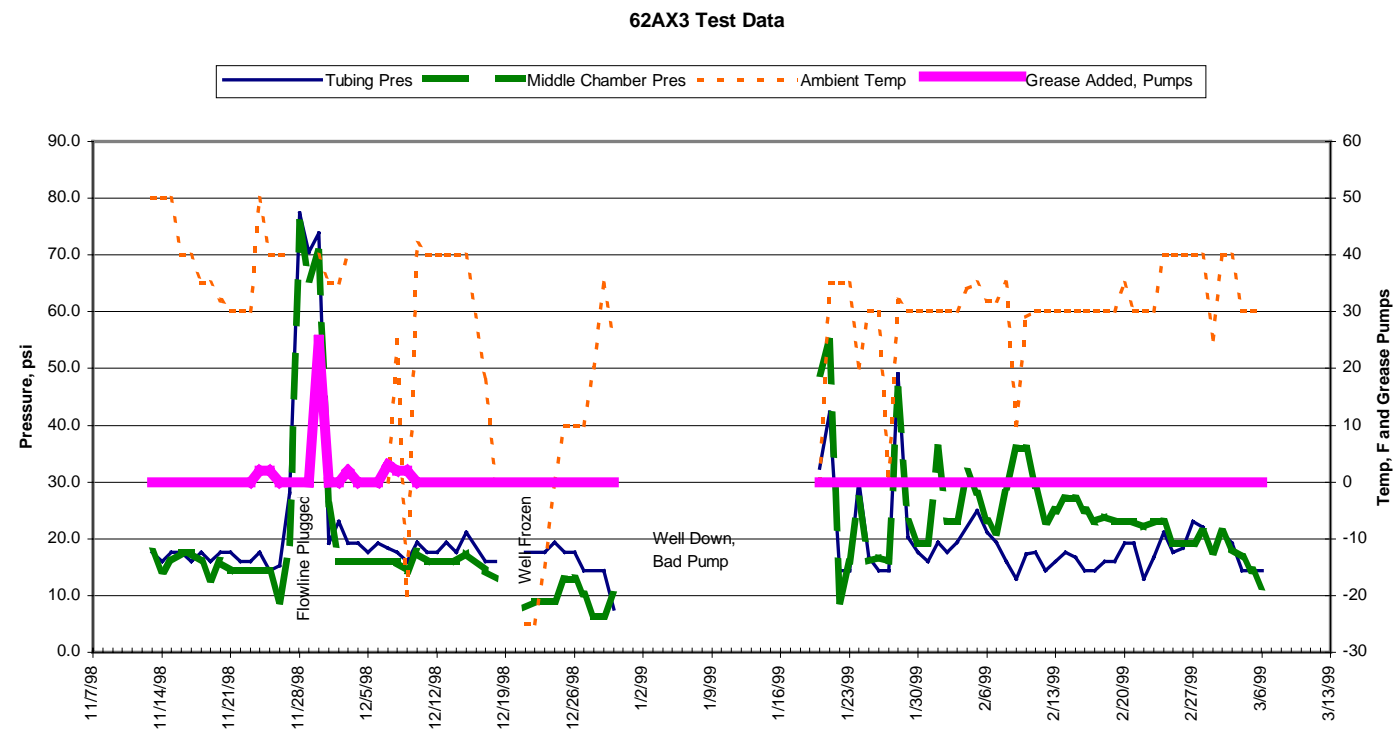

Figure 5 Well 62AX3 (Grease Version) Test Results

\section{Well 62AX3}

It can be seen from Figure 5 that the middle chamber pressure tracks the changes seen in the tubing pressure. On November 28, 1998, the flowline plugged up with paraffin and caused the tubing pressure to rise drastically from 16 psi to approximately 73 psi. The middle chamber pressure likewise rose. However, during the event, a half tube of grease was used. About three pumps of grease were noted on top of the stuffing box. This amount of leakage was considered small compared to what would have been expected from a conventional stuffing box. It was the only leakage observed from the top of the stuffing box during the term of the test. It is not clear why the majority of the grease leaked into the tubing when the tubing pressure was so high.

On December 18, 1998, extremely cold weather caused the well to freeze up. Although production was down for several days, there was no effect on the stuffing box. A lower-temperature grease was obtained to prevent solidification in the middle chamber. As long as the well was pumping, polished rod temperature held constant at 50 degrees $\mathrm{F}$. When the well thawed out and started pumping again on December 21, it was discovered that the pump was bad. The well was 
shut down until January 20,1999, when the pump was replaced and the well returned to production. The packing on the primary seal was tightened up slightly. A half tube of grease was added when the stuffing box was installed.

When the well was returned to production, the middle chamber pressure was maintained above the tubing pressure. This is thought to be a function of the tightness of the primary packing. There was no further grease usage, and no further leakage observed on the top of the stuffing box. Data was collected until March 6, 1999.

\section{Well 12AX11}

When 12AX11 started operation with the Hydro-Balanced Stuffing Box, a nitrogen source was required to maintain the middle chamber pressure above the tubing pressure. On November 24, 1998 when the nitrogen pressure was initially applied, the fluid in the middle chamber was quickly forced into the tubing. Within 4 or 5 pump strokes, the entire fluid reservoir was used up. The pressure on the nitrogen bottle regulator was decreased to $5-15$ psi above the tubing pressure. Fluid leakage was decreased to 2 inches in a 24 hour period. Nitrogen pressure was removed during the Thanksgiving holiday weekend to prevent any potential damage to equipment. Nitrogen was reapplied on December 2, 1998. This time the regulator pressure was reduced to 45 psi. An inch of fluid was used overnight. On December 10, the nitrogen pressure was reduced to $42 \mathrm{psi}$. Tubing pressure was ranging from 36 to $41 \mathrm{psi}$. The safe fluid level seemed to stabilize. Test results are shown in Figure 6.

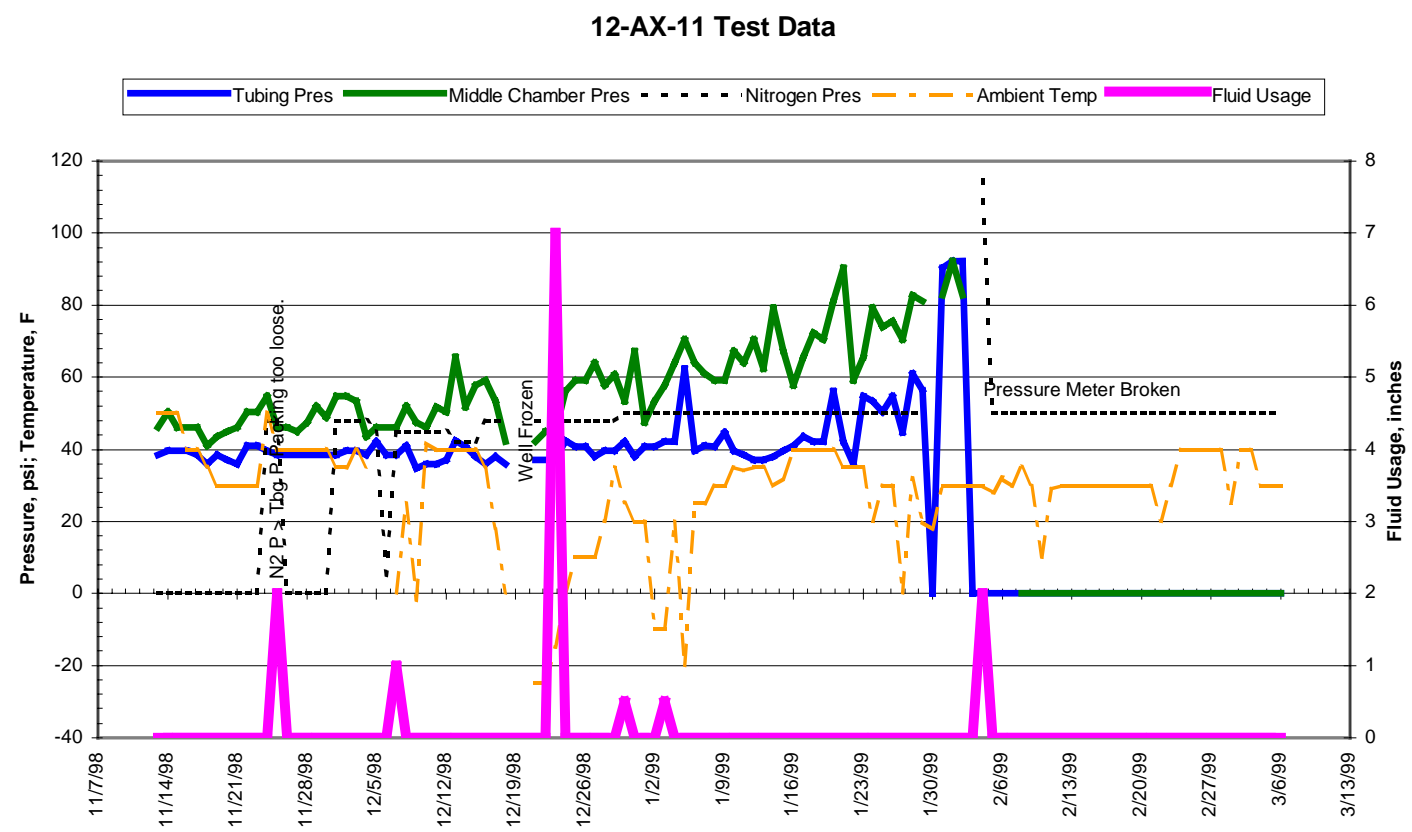

Figure 6 Well 12AX11 (Oil Version) Test Results 
On December 15, 1998, the primary packing was tightened and the nitrogen pressure again raised to 48 psi. Performance was good until December 19, when the weather turned extremely cold. The well froze up. When it was restarted on December 23, there was considerable loss of fluid both on top of the stuffing box and into the well fluids until the polished rod warmed up to its normal operating temperature of 50 degrees $\mathrm{F}$. The upper and lower packing elements were tightened up. By the time the stuffing boxes were tightened, there was seven inches of fluid lost. The well operated for 8 hours before freezing up again. The next morning, the well was restarted without incident. There was no further fluid leakage.

From this point on until the end of January, the stuffing box operated without requiring any additional fluid or showing any signs of leakage. Nitrogen pressure was maintained at $48 \mathrm{psi}$, while the tubing pressure stayed in the low to mid forties.

In early February, the flowline began to experience plugging from paraffin. Tubing pressures spiked near $100 \mathrm{psi}$, while the middle chamber pressure reached 170 psi. This was in excess of the limit of the Barton pressure recorder, and the meter was damaged. Associated with this event was the usage of 2" of fluid. There was evidence that the majority of the leaked fluid was through the primary packing. The flowline was treated with hot water to remove the paraffin plugs. The safe fluid reservoir was refilled, and the nitrogen pressure was reset at 50 psi. The stuffing box continued to operate until March 6, 1999 with no further fluid usage or leakage.

\section{Test Conclusions}

1. The stuffing box is capable of providing a better seal between well fluids and the environment than conventional stuffing boxes. It allows the polished rod to operate cooler and with lubrication, extending the life of the packing elements, and reducing the amount of attention required to prevent leakage.

2. It is important to tighten the packing elements correctly. This prevents loss of safe fluid from the inner chamber to either the environment or to the well fluids below. Tightening the primary packing correctly also helps to maintain the inner chamber pressure above the tubing pressure for proper stuffing box operation. When the packing bolts were tightened the exact same distance using a ruler, better performance was obtained.

3. When the Hydro-Balanced Stuffing Box is installed and adjusted properly, it is capable of significantly reduce the spillage of well fluids from the stuffing box for rod pumped wells, compared to the conventional stuffing box design. The lubrication system should also result in energy savings for the pump motor. 


\section{Recommendations}

1. It is recommended that the manufacturer develop better procedures for tightening the packing elements. This is a very crucial part of the proper operation of the stuffing box. It is recommended that initial tightening should be between two and three turns from totally tight.

2. Because of the lack of much more tightening ability on the packing elements, it is recommended that the packing mechanisms be redesigned to allow more travel to keep the elements tight as they wear later in their life.

3. Since the packing elements seemed to respond well to be tightened equally, there should be some measuring device on the bolts to aid the equalization. An etched or engraved ruler would be helpful.

4. A nut should be threaded on the bottom of the grease level indicator to prevent it from being ejected during the refilling process. 